\title{
Zoom in the attitude-behaviour gap: low carbon travel behaviour
}

\author{
Yingying Jin ${ }^{1, *}$ Jingjing Yang ${ }^{2}$, and Jin $\mathrm{Hu}^{3}$ \\ ${ }^{1}$ Zhejiang Academy of Culture \& Tourism Development, Tourism College of Zhejiang, China \\ ${ }^{2}$ Macao Institute for Tourism Studies, China \\ ${ }^{3}$ JiHe Travel Ltd, China
}

\begin{abstract}
The concept of pro-environmental behaviour in low carbon consumption has increasingly attracted academics' attention in the last two decades. There has been a growing interest in exploring the association between people's travel attitude and behaviour. This study has critically reviewed, compared, and discussed some of the key theories around these research topics. However, based on the findings of the literature review, there is a dearth of research examining the association between people's travel attitude and their actual behaviour. Therefore, this study seeks to fill the gap by examining the causal linkage between people's attitude towards a specific travel mode and their actual travel behaviour.
\end{abstract}

\section{Introduction}

Following the waves of agricultural civilisation, industrialisation and informationisation, the low-carbon economy is another significant civilisation [1,2]. Lowcarbonisation has been promoted as an essential way to deal with climate change $[1,2,3,4]$. A low carbon economy consists of three elements: macroscopic low carbon decision-making, microcosmic low carbon production and low carbon consumption [2]. According to Baeumler et al., the world will be highly urbanised with 70 percent of the world population residing in urban areas [5]. Hence, consumer behaviour changes to adopt a sustainable lifestyle is urged $[5,6]$.

It is important to focus on environmentally significant behaviour based on its impacts prior to exploring antecedents or designing a behavioural change intervention in order to maximise its benefits $[7,8,9,10$, 11]. Therefore, this study emphasises on daily travel behaviour due to its significant environmental impact [12, 13]. It is urged that by 2050 , there is a need to reduce transport emissions by at least $50 \%$, because in developed countries it contributed to approximately $30 \%$ of anthropogenic $\mathrm{CO} 2$ emissions, and globally, nearly $23 \%$ emissions [14, 15]. Accordingly, a transition to proenvironmental travel behaviour is recommended as one of the most effective ways to combat the climate change [16, $13,15]$.

The antecedents of travel choices that either encourage or hinder pro-environmental behaviour can be broadly grouped into three categories: demographic factors, internal factors, external factors. Gender is one of the most discussed demographic factors in the literature. Some academics suggest that female have a greater tendency to adopt environmental behaviour than male due to their higher emotional engagement and environmental concerns, as well as having weaker car habits and lesser attachment to technological solutions [17, 18]. Others argue that different social roles can lead to different patterned behaviours such as married women tend to travel more to places such as supermarkets and schools as they have been assigned to more household responsibilities than men [19]. Moreover, elder, single and low-income people have a greater tendency towards sustainable transport mode because they have less appliances [20]. Accordingly, travel choices can be influenced by the differences between gender, household responsibility and lifestyle.

Despite the socio-demographic factors, theory of planned behaviour (TPB) is widely cited framework in environmental studies [21, 22]. It is suggested that there are three key factors influence behavioural intentions: perceptions of behavioural control and social norms, and attitudes toward the behaviour [21]. However, proenvironmental travel behaviour is complex which cannot simply use the linear attitude-behaviour nexus to explain. Researchers such as Barr et al. have all denied such association as they found that even an environmentalist would not behave pro-environmentally at all times $[23$, 24].

A high attitude-behaviour association could only be achieved when measuring these two variables on the same level [24]. This is supported in numbers of related studies which have all indicated that a particular proenvironmental behaviour is better predicted by its behavioural related attitudes than general environmental attitudes $[24,22]$. This is because that the contextual and behavioural spill-over effects of such general attitudes are very weak [25]. However, research reveals that individuals' socio-demographic and socio-economic characteristics could influence their travel behaviours differently, but have no effect in their attitudes as it's only related to unsustainable travel behaviours [26]. Accordingly, this study is set to examining the existence

* Corresponding author: jin_yingying18@163.com 
of a causal linkage between the attitude of a particular behaviour and the actual travel behaviour.

Individual's behaviour could also be influenced by external factors such as institutional, social, and cultural factors. Institutional factors such as public infrastructures are key to encourage pro-environmental behaviour [17]. Furthermore, although economic, social, and cultural factors have a great influence in behaviour change, they are interrelated with internal factors. Therefore, the distinction between them is blurred.

\section{Materials and Methods}

Rajecki [27] opined that attitude-behaviour measurement and temporal discrepancy are two important research limitations in behavioural studies. This reference is relative dated, but the limitations are still remained valid $[7,24,8]$. This is because attitude and behaviour are constantly changing [24, 10]. Therefore, the challenge is to design a valid way to examining attitude-behaviour relationship [17]. Accordingly, this research attempts to address the two methodological limitations by examining the nexus between daily travel attitude and actual travel action, and the effectiveness of integrated interventions.

This research is part of a larger study [28]. Two datasets were used in this research: a secondary longitudinal dataset and an online survey dataset. SPSS programme was used to analysis both datasets. Nonparametric measures were used because the longitudinal data was not normally distributed. The survey data was collected by using online questionnaire with the help of the organisation. The technique of self-selection sampling was used to select respondents. The collaborating organisation approach their members on behalf of the researcher to circulate questionnaire via email.

The secondary longitudinal data is provided by the collaborate organisation which is a self-reported survey dataset of Eco Rewards members' weekly travel behaviour over the period of 27 weeks prior to the data analysis. The survey data is mainly used to investigate the respondents' travel attitude and antecedents of their travel behaviour. The online survey consists of 18 questions which is organised into three parts. The first part includes a range of attitudinal questions in relation to behavioural change strategies and different transport modes which was selected and tailored based upon Prillwitz and Barr's [26] questionnaire. The second part contains open and closed questions in order to examine respondents' travel behaviour prior to partaking in the Eco Rewards scheme and their experience with the scheme. Content analysis and frequency test were used to analyse the data collected from open-ended questions. The final part investigates participants' basic socio-demographic characteristics.

There were 65 respondents take part in this study wherein 39 males and 26 females, age ranging from 16 to $74,40 \%$ were aged between $45-59$ and over $30 \%$ of them aged between $30-44$, only two participants failed under the age group of 16-19. Accordingly, there is a likelihood of sample bias towards the middle age groups of 30 to 59 . Over $65 \%$ of the participants were married, followed by $21.5 \%$ single and $7.7 \%$ divorced. Over $35 \%$ of participants had before tax annual income of $£ 40,000$ or above, $20 \%$ of them had $£ 20,000-£ 29,999$. There were roughly equal proportion of participant that either living with or without children.

\section{Results \& Discussion}

To examine the linkage between the attitude of a particular behaviour and the actual travel behaviour, the first step is to revel the relevant attitudinal factors. Eight behaviour-related attitudinal factors (see Table 1) were identified through factor analysis. Kendall's tau correlation was used to measure the attitude-behaviour nexus and found no significant relationships between them. Accordingly, attitudes have no significant influence on people's actual travel behaviour.

Table 1 Attitudinal factors

\begin{tabular}{|c|c|c|c|c|c|c|}
\hline & Factor & Item with highest loading & $\begin{array}{l}\text { No. of } \\
\text { items }\end{array}$ & $\begin{array}{l}\text { Highest factor } \\
\text { loading }\end{array}$ & $\begin{array}{l}\text { Eigen } \\
\text { value }\end{array}$ & $\begin{array}{l}\text { Cronbach's } \\
\text { Alpha }\end{array}$ \\
\hline \multirow[t]{2}{*}{$\begin{array}{l}\text { Green } \\
\text { travel }\end{array}$} & Pro-environment & $\begin{array}{l}\text { Walking and/or cycling will help to tackle } \\
\text { problems like climate change }\end{array}$ & 7 & .849 & 5.961 & .887 \\
\hline & $\begin{array}{l}\text { Aspiring green } \\
\text { traveller attitudes }\end{array}$ & $\begin{array}{l}\text { There is a good level of information about } \\
\text { walking and cycling routes and facilities }\end{array}$ & 6 & .762 & 2.005 & .787 \\
\hline \multirow{2}{*}{$\begin{array}{l}\text { Public } \\
\text { transport }\end{array}$} & Pro-environment & I feel morally obliged to use public transport & 8 & .935 & 5.711 & .852 \\
\hline & $\begin{array}{l}\text { Public transport } \\
\text { user attitudes }\end{array}$ & Using public transport is convenient & 6 & .785 & 2.112 & .837 \\
\hline \multirow[t]{2}{*}{ Car travel } & Pro-car attitudes & The car offers the greatest travel choices & 6 & .749 & 4.835 & .824 \\
\hline & $\begin{array}{l}\text { Addicted car user } \\
\text { attitudes }\end{array}$ & Using a car is the safest travel choice & 7 & .735 & 2.487 & .810 \\
\hline \multirow[t]{2}{*}{ Strategy } & $\begin{array}{l}\text { Supportive } \\
\text { intervention }\end{array}$ & $\begin{array}{l}\text { Provide more information about the average rate } \\
\text { (benchmark) of my local community's use of } \\
\text { different travel options }\end{array}$ & 5 & .828 & 3.580 & .802 \\
\hline & $\begin{array}{l}\text { Motivational } \\
\text { intervention }\end{array}$ & $\begin{array}{l}\text { Provide more financial incentives to people who } \\
\text { walk / and or cycle }\end{array}$ & 2 & .777 & 1.484 & .750 \\
\hline
\end{tabular}

Source: Authors' calculations based on survey data.

This resonates with Juvan and Dolnicar's [23] finding that there is no linear attitude-behaviour relationship. However, it contradicts with the prediction made by
Böhler et al. [24] that these two variables can be highly correlated when they are being measured on the same level. Likewise, this research also refutes studies of which 
suggest that behaviour-specific attitudes can result in proenvironmental behaviour [26]. Moreover, the findings revealed that women were more engaged in green travel modes than men. However, in this study, the proportion of male respondents was larger than females. Accordingly, these contradictory findings might occur due to different adoption of sampling and analysis techniques. The insignificancy might due to small sample size and the unequal gender between respondents. However, the focus of this study is to examine the attitude-behaviour relationship, not the link between gender and attitude, which can be studied in future research.

Despite the argument on attitude-behaviour relationship, socio-demographic factor as a key behavioural measure has also been assessed in this study. The relationship between the socio-demographic characteristics of participants and their travel behaviours were examined using non-parametric tests. Many studies $[17,20]$ have found that socio-demographic factors can have various influence on travel choice. Unexpectedly, no statistically significant differences were found between participants' socio-demographic characteristics (i.e., age, marital status, household responsibilities, income, car availability, and travel distance) and their travel behaviours in this study. However, intrinsic factors such as peoples' perceptions and attitudes are difficult to change [11]. Therefore, external factors become vital to encourage pro-environmental behaviour which could also indirectly interfering attitudes and intrinsic motivations.

The findings also revealed that convenience and travel cost are two external factors which mostly influence participants' travel decision-making, while intrinsic factors such as moral and environmental concerns are least important (see figure 1).

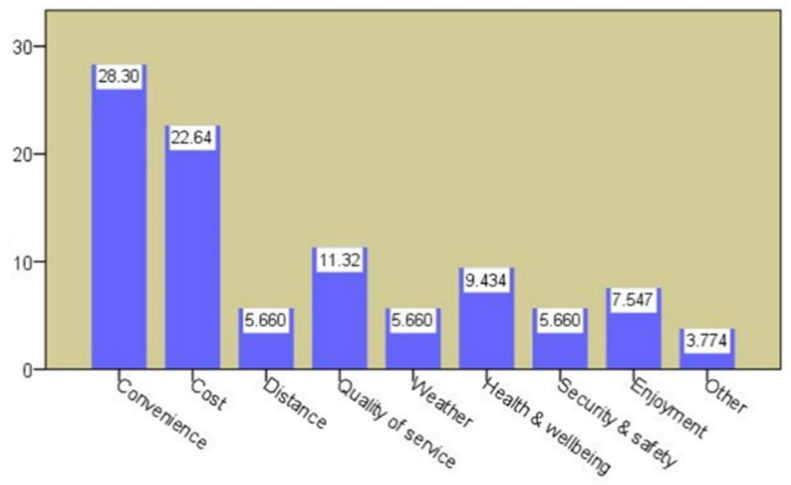

Figure 1 Other travel motivational factors

This resonates with previous studies which suggest that travel attitude has no significant influence on travel behaviour [11, 26]. It also echoes Kollmuss and Agyeman's [17] research that institutional factors are fundamental to encourage pro-environmental behaviour, as some participants stated:

"Convenience of connections from A to B. Sometimes you have to drive as there are no other options via public transport to reach a destination".

"I would use public transport/bus locally if there is a good network bus route... buses at the moment are far too expensive to use daily to commute, it will work out more expensive than running a car and a big disadvantage for being inconvenient".

"It would depend on the distance I live from work and the public transport links and whether it is cost effective".

The above three extracts illustrate that institutional factors such as public transport links and travel expenses are crucial for people to partake in green travel. Larsen and Guiver [29] also revealed similar findings which suggest that travel distance is the most factor in travel decision-making, especially in relation to its associated concerns, the involved travel time and costs. The cost in here not only refers to economic cost, but also the associated benefits and intangible experience, as some participants commented:

"If people were of the opinion that cycling is a safe and healthy option more of them would consider it".

"I also cycle to work 2 or 3 days a week which I do for enjoyment, health benefits...".

"Ability to work, rest and chat on train is important for my typical week".

These extracts are in consistent with Larsen and Guiver's [29] research which suggest that proenvironmental travel behaviour could be encouraged by reducing the time cost and promoting slow travel. Besides convenience and costs, participants also concerned with the security and safety issues associated with cycling. For example, the lack of separated cycling routes, bicycle storage space, poor road condition for cycling, and the absence of code of conduct to improve the cycling environment for both cyclists and drivers, as well as their road manner.

\section{Conclusions}

No relationship was found between people's travel attitude and their actual travel behaviour. Although the finding shows that female tend to engage more on green travel. However, such differences between sociodemographic characteristics (e.g., gender, age, income, age, marital status, and travel distance) and other travel behaviours (i.e., public transport and car travel) were insignificant. Moreover, many people find it hard to adopt a low-carbon lifestyle as their performance of low carbon travel behaviour was mainly influenced by institutional factors such as travel convenience and costs. Therefore, to maximise the efficacy of a behaviour change intervention, a close cooperation between private and public sector is recommended by addressing the most concerned factors such as the supply of public transport and travel costs.

\section{Reference}

1. Z. Tang, C. Shi and Z. Liu, "Sustainable development of tourism industry in China under the low-carbon economy," Energy Procedia, vol. 5, pp. 1303-1307, 2011.

2. M. Zhang and X. Huang, "Research on the concept system and construction pattern of low carbon tourism based on low carbon economy," in Proceedings of 2011 International Conference on 
Remote Sensing, Environment and Transportation Engineering, Nanjing, China, 2011.

3. X. Peng and J. Zhou, "Pattern of China's ecotourism resources in low carbon economy," Applied Mechanics and Materials, Vols. 291-294, p. 14511454, 2013.

4. W. Yang, "The development of tourism in the low carbon economy," International Business Research, vol. 3, no. 4, pp. 212-215, 2010.

5. A. Baeumler, E. Ijjasz-Vasquez and S. Mehndiratta, Sustainable low-carbon city development in China, Washington DC: World Bank Publications, 2012.

6. T. Jackson, Motivating Sustainable Consumption: A Review of Evidence on Consumer Behaviour and Behavioural Change, London: Sustainable Development Research Network, 2005.

7. K. Armel, K. Yan, A. Todd and T. Robinson, "The Stanford Climate Change Behavior Survey: Assessing Greenhouse Gas Emissions-Related Behaviors in Individuals and Populations," Climatic Change, vol. 109, no. 3/4, p. 671-694, 2011.

8. J. Dono, J. Webb and B. Richardson, "The Relationship Between Environmental Activism, Pro-Environmental Behavior and Social Identity," Journal of Environmental Psychology, vol. 30, no. 2, p. 178-186, 2010.

9. B. Gatersleben, L. Steg and C. Vlek, "Measurement and Determinants of Environmentally Significant Consumer Behavior," Environment and Behavior, vol. 34, no. 3, p. 335-362, 2002.

10. L. Steg and C. Vlek, "Encouraging proenvironmental behaviour: An integrative review and research agenda," Journal of Environmental Psychology, vol. 29, no. 3, p. 309-317, 2009.

11. E. Geller, "The challenge of increasing proenvironment behavior," in Handbook of environmental psychology, New York, NY, Wiley, 2002, p. 525-540.

12. R. Kemp and J. Rotmans, "Managing the transition to sustainable mobility," in System innovation and the transition to sustainability: theory, evidence and policy, Cheltenham, Edward Elgar, 2004, p. 137167.

13. M. Nilsson and R. Küller, "Travel behaviour and environmental concern," Transportation Research Part D: Transport and Environment, vol. 5, no. 3, pp. 211-234, 2000

14. OECD, "Greenhouse Gas reduction strategies in the transport sector," OECD, Paris, 2008.

15. UNECE, "Climate Change and Sustainable Transport. from," UNECE, 2015. [Online]. Available: $\quad$ http://www.unece.org/?id=9890. [Accessed 17 October 2018].
16. G. L. Markle, "Pro-Environmental Behavior: Does It Matter How It's Measured? Development and Validation of the Pro-Environmental Behavior Scale (PEBS)," Human Ecology, vol. 41, no. 6, p. 905914, 2013.

17. A. Kollmuss and J. Agyeman, "Mind the Gap: Why Do People Behave Environmentally and What are the Barriers to Pro-Environmental Behaviour," Environmental Education Research, vol. 8, no. 3, p. 239-260, 2002.

18. E. Matthies, S. Kuhn and C. Klöckner, "Travel Mode Choice of Women the Result of Limitation, Ecological Norm, or Weak Habit?" Environment and Behavior, vol. 34, no. 2, p. 163-177, 2002.

19. A. Eagly, W. Wood and A. Diekman, "Social role theory of sex differences and similarities: a current appraisal," in The Developmental Social Psychology of Gender, Hillsdale, NJ, Lawrence Erlbaum, 2000, p. $123-136$.

20. W. Poortinga, L. Steg, C. Vlek and G. Wiersma, "Household preferences for energy-saving measures: A conjoint analysis," Journal of Economic Psychology, vol. 24, no. 1, p. 49-64, 2003.

21. I. Ajzen, "The theory of planned behavior," Organizational Behavior and Human Decision Processes, vol. 50, no. 2, p. 179-211, 1991.

22. S. Lin, "The gap between global issues and personal behaviors: Pro-environmental behaviors of citizens toward climate change in Kaohsiung, Taiwan," Mitigation and Adaptation Strategies for Global Change, vol. 18, no. 6, p. 773-783, 2013.

23. E. Juvan and S. Dolnicar, "The attitude-behaviour gap in sustainable tourism," Annals of Tourism Research, vol. 48, p. 76-95, 2014.

24. S. Böhler, S. Grischkat, S. Haustein and M. Hunecke, "Encouraging environmentally sustainable holiday travel," Transportation Research Part A: Policy and Practice, vol. 40, no. 8, pp. 652-670, 2006.

25. J. Thøgersen and F. Ölander, "Spill over of environment-friendly consumer behaviour," Journal of Environmental Psychology, vol. 23, no. 3, p. 225-236, 2003.

26. J. Prillwitz and S. Barr, "Moving towards sustainability? Mobility styles, attitudes and individual travel behaviour," Journal of Transport Geography, vol. 19, no. 6, p. 1590-1600, 2011.

27. D. W. Rajecki, Attitudes: themes and advances, Sunderland, MA: Sinauer, 1982.

28. Y. Jin, "Dissertation: An exploration into the effect of different tools on encouraging pro-environmental behaviour," University of Surrey, Guildford, 2015. 
29. G. Larsen and J. Guiver, "Understanding tourists' perceptions of distance: A key to reducing the environmental impacts of tourism mobility," Journal of Sustainable Tourism, vol. 21, no. 7, p. 968-981, 2013.

30. S. Barr, G. Shaw, T. Coles and J. Prillwitz, "A holiday is a holiday': practicing sustainability, home and away," Journal of Transport Geography, vol. 18, p. 474-481, 2010. 